\title{
Polishing the Teaching of Affective Domain in Online Education
}

\author{
Tayyeba Iftikhar Mirza ${ }^{1}$ and Usman Mahboob ${ }^{2}$ \\ ${ }^{1}$ Department of Medical Education, Foundation University Medical College, Islamabad, Pakistan \\ ${ }^{2}$ Institute of Health Professions Education and Research, Khyber Medical University, Peshawar, Pakistan
}

\begin{abstract}
The COVID-19 pandemic has affected the overall education system in general and medical education in particular. While the cognitive and psychomotor domains were regularly taught in most medical schools, the affective domain was mostly left to informal teaching through role modelling. With the switch to online teaching, the dynamics of role modelling has changed, and the students do not observe their clinical teachers communicating with patients and colleagues. Therefore, the affective domain now needs to be taught more explicitly than ever to inculcate empathy, integrity, motivation, confidence, communication, time management, teamwork, advocacy, and respect. The five levels of affective domain namely; receiving, responding, valuing, organising and characterisation, can be taught to some extent. This paper describes the different strategies which can be utilised for online education for each level of the affective domain, and help students learn valuing emotions of others, that is an essential attribute required by a competent physician.
\end{abstract}

Key Words: Affective domain, Teaching, COVID-19, Undergraduate medical students.

How to cite this article: Mirza TI, Mahboob U. Polishing the Teaching of Affective Domain in Online Education. J Coll Physicians Surg Pak 2021; 31(04):485-486.

The COVID-19 pandemic has affected the education system in general and medical education in particular. While the cognitive and psychomotor domains were regularly taught in most medical schools, the affective domain was mostly left to informal teaching through role modelling. ${ }^{1}$ With the switch to the online teaching, the dynamics of role modelling has changed and the students do not observe their clinical teachers communicating with patients and colleagues. Therefore, the affective domain now needs to be taught more explicitly than ever to train the future physicians with appropriate behaviours such as empathy, integrity, motivation, confidence, communication, time management, teamwork, advocacy, and respect. Most of these behaviours can be addressed by online education, making necessary changes in the medical curricula. Medical curricula, although are quite fixed and resist changes due to robust control by the assessment system. Hence, without changing the outcomes and influencing assessment, the same content can be taught with certain contextual modifications to adjust into the online education.

Correspondence to: Dr. Usman Mahboob, Institute of Health Professions Education and Research, Khyber

Medical University, Peshawar, Pakistan

E-mail: usman.mahboob@kmu.edu.pk

Received: July 11, 2020; Revised: November 09, 2020;

Accepted: December 10, 2020

DOI: https://doi.org/10.29271/jcpsp.2021.04.485
Digital educational technology plays a substantial role in the lives and works of both learners and faculty in higher education. Web tool-use helps in refining self-identity, social identity, and experience of social relationships within particular places. ${ }^{2}$ Millennial and digital generations expect from their teachers to use new digitally mediated approaches to learning. Faculty development has an important role in improving the quality of online teaching. This can be done through online workshops, using different web tools. In developing countries like Pakistan, self-directed technology training programme can be used in which employees are given incentives for exploring technology. The use of wikis, blogs and podcasts have increased over a short period of time because all are relatively easy to use. There are many free and open-source versions of these tools, which might be the reason for their explosive growth. Thus, it would be relatively easy to implement any or all within a health professions' educational environment.

This paper describes the different strategies, which can be utilised for online education for each level of the affective domain, and help students learn valuing others' emotions, which is an essential attribute required by a competent physician.

A recent study in Pakistan reported that the overall level of empathy among undergraduate medical students is low, and it further decreases with time, due to deficiency in addressing the affective domain in the formal curriculum. ${ }^{3}$ Hence, it is important to explicitly teach the affective domain, and include teaching sessions for it in the timetables. Moreover, medical curricula also 
need modifications in teaching strategies according to the current situation, to address the five levels of the affective domain.

The initial two levels of the affective domain are receiving and responding, which include listening and speaking to others, respectfully. These two levels can be taught by consistently reinforcing that everyone in the online class has a right to be heard, but not at the expense of speaking out of turn or over someone else. This is similar to the etiquettes in the routine classroom environment. Moreover, to make teaching explicit, the students can be shown videos of different life stories and narratives. A case can be uploaded, and through the discussion forum, students' views can be obtained, providing a powerful reflective experience. Additionally, questions can be asked in rounds to initiate discussion where one student starts a question. Then the students, who are tagged, respond and ask a question to the person that s/he tags. The next question needs to be in some way related to the first question. All students get a chance to ask and respond.

The third level of the affective domain is valuing that can be taught using problem-solving situations to help students value emotions. Synchronous collaboration tools that can be used effectively for online PBL are chat, shared whiteboards, video conferencing, and group browsing. These tools ensure collaboration within the problem-based learning team. Facilitators can also plan real-time sessions with the online PBL team to engage a student in discussion and facilitate the learning. ${ }^{4}$ Moreover, another strategy is to get feedback from students about content, format, and pacing, which are essential to give them a sense of ownership. Students can review peer answers and then provide feedback and ask questions. This can be done using WhatsApp and Slack. Slack is a digital workspace that lets users work together in teams. Slack works more efficiently than platforms like Facebook and Twitter, which build is a better-off knowledge-sharing environment. ${ }^{5}$ This online peer feedback is also helpful in creating connections between students. Furthermore, the critique opportunities using blogs, wikis, and podcasting help students value others opinion.

The higher levels - four and five of the affective domains - are organisation and characterisation that can be taught through reflective writing. Reflecting through writings, help student think deeply on taught behaviours, refining their attitudes, acquiring virtues, and integrating values. The clinical teachers can bring patients to the virtual class; and the students can be asked to take a history from the patient. The students witness online interaction of physician with the patient followed by a reflective narrative on what they had witnessed. Moreover, telemedicine is one of the powerful tools in the current situation; and the students can help and guide patients regarding their diseases under supervision, or can help them in booking appointments. Moreover, medical students can interview patients over a live video stream to learn about patient experiences and health, and to write narratives addressing the aspects of professionalism and ethics. ${ }^{6}$ Likewise, online role-playing can be used where one student volunteers to be a patient and the rest of students practise asking questions as part of a case history, and then roles can be reversed. Roleplay can be used to practice counselling. Online roleplay experience provides real-world relevance, depending upon the degree to which students logically take on the roles they had been assigned. Further, simulation scenarios can be designed to represent patient care situations to which the students respond acting as practising physicians.

The affective domains encompass both the cognitive and the psychomotor domains and not explicitly teaching it may lead to the production of doctors without empathy. The suggestions, which are given for teaching each level of the affective domain are a step towards the exploration of more strategies, and to further improve the learning of the affective domain.

\section{PATIENTS' CONSENT:}

Notapplicableas there was no data collected from patients.

\section{CONFLICT OF INTEREST:}

Both authors did not declare any conflict of interest.

\section{AUTHORS' CONTRIBUTION:}

TIM: Conceived the idea, wrote the first draft and edited all drafts. UM: Designed the format of the paper, did the relevant literature search, drafted the article and edited all drafts.

\section{REFERENCES}

1. Pagatpatan CP, Valdezco JAT, Lauron JDC. Teaching the affective domain in community-based medical education: $A$ scoping review. Med Teach 2020; 42(5):507-14. doi.org/ 10.1080/0142159X.2019.1707175

2. Mapuva J, Stoltenkamp J, Muyengwa L. Blogs, wikis, podcasts: Harnessing technology for enhanced learning achievement through powerful web tools 2010; 7(12). www.itdl.org/Journal/Dec_10/article01.htm

3. Shaheen A, Mahmood M, Miraj M, Ahmad M. Empathy levels among undergraduate medical students in Pakistan, a cross-sectional study using jefferson scale of physician empathy. J Pak Med Assoc 2020; 70(7):1149-53.

4. Richardson JC. Book Review: A practical guide to problembased learning online. Vol. 3. Interdisciplinary Journal of Problem-Based Learning 2009; 3(1): doi.org/10.7771/ 1541-5015.1089

5. Vela K. Using slack to communicate with medical students. J Med Libr Assoc 2018; 106(4):504-7. doi: 10.5195/jmla. 2018.482.

6. Waseh S, Dicker AP. Telemedicine training in undergraduate medical education: Mixed-methods review. J Med Internet Res 2019; 21(4):1-9. doi: 10.2196/12515. 